\title{
MIASTENIA GRAVIS
}

\section{RESULTADOS DE TIMECTOMIA EM 52 PACIENTES}

\author{
JOSÉ TEOTONIO DE OLIVEIRA*, GILBERTO BELISÁRIO CAMPOS*, \\ FRANCISCO EDUARDO C. CARDOSO*
}

\begin{abstract}
RESUMO - Durante o periodo de 1971 a 1993, 52 miastênicos sem timoma ( 7 homens e 45 mulheres ) foram timectomizados por via esternal. Os resultados foram classificados em remissão e não-remissão . A taxa de remissāo foi $48 \%$. No grupo de remissōes havia 5 homens e 20 mulheres. O tempo de seguimento foi de 5,5 anos em ambos os grupos. Os pacientes foram classificados clinicamente segundo a classificação de Osserman. De 16 pacientes na categoria II A, 11 entraram em remissāo; de 36 pacientes nas categorias II B e III, 14 entraram em remissāo.O tempo de duração de doença foi de 1,8 e 4,3 anos nos grupos de remissōes e nãoremissōes, respectivamente. Todos os pacientes que entraram em remissão tinham menos de quatro anos de doença. Dos 43 pacientes com menos de quatro anos de doença, $42 \%$ não apresentaram remissão significando que um tempo de doença de menos de quatro anos nāo é indicador de remissão. Nossos dados indicam um melhor prognóstico quando a timectomia é feita nos primeiros quatro anos de doença.
\end{abstract}

PALAVRAS-CHAVE : miastenia gravis, timectomia

\section{Myasthenia gravis: results of thymectomy in 52 patients}

SUMMARY - From I971 to 1993, 52 myasthenics without thymomas ( 7 men and 45 women) were thymectomized.The results were categorized in remissions and non-remissions. The remission rate was $48 \%$.In the remission group there were 5 men and 20 women and in the non-remission group 2 men and 25 women. The follow-up time was 5.5 years in both groups. There were 16 patients in Osserman category II A, 11 achieving remission; 36 patients were in categories IIB and III, and 14 achieved remission. The duration of disease was 1.8 years and 4.3 years in the remission and non-remission groups, respectively. All patients with remission had less than four years of disease but among the 43 patients with less than four years of symptoms, $42 \%$ did not achieve remission. Our data reinforce the need for early thymectomy in myasthenia gravis.

KEY WORDS: myasthenia gravis, thymectomy

A miastenia gravis (MG) é doença neurológica rara, com incidência de 4,4/1.000.000²5 e prevalência entre 50 a 125 casos por um milhão de habitantes ${ }^{5.25}$. Um neurologista, em média, verá um caso a cada três anos ${ }^{16}$, de modo que somente em centros especializados há oportunidade de se ver um número elevado de casos. A doença é caracterizada por fraqueza muscular flutuante que pode acometer a musculatura ocular, bulbar ou sistêmica. De acordo com Oosterhuis ${ }^{17}$, a história natural da MG , sem outro tratamento que anticolinesterásicos, apresenta uma remissão de $20 \%$ e uma mortalidade de $25 \%$. As várias formas de terapia, como timectomia, imunossupressão, assistência respiratória e controle de infecções, afetaram sensivelmente a história natural da MG. Assim, no presente, a mortalidade é praticamente zero e a grande maioria dos pacientes tem vida normal ${ }^{5}$.

* Serviço de Neurologia do Hospital das Clínicas da Universidade Federal de Minas Gerais (UFMG). Aceite: 18 - outubro - 1994.

Dr. José Teotonio de Oliveira - Av. Getúlio Vargas, 67 - 30112-020 Belo Horizonte MG - Brasil. 
Embora a timectomia seja uma forma de tratamento da MG aceita há muitos anos, ainda existem controvérsias a respeito de suas indicações e resultados. $O$ presente estudo apresenta os resultados de timectomia em 52 pacientes miastênicos no período de 1971 a 1993, sendo avaliadas as características do grupo com remissão.

\section{PACIENTES E MÉTODOS}

Cinquenta e oito pacientes com MG generalizada sem timoma, foram timectomizados no periodo de 1971 a 1993, dos quais 52 têm dados suficientes para análise. O diagnóstico de MG foi feito clinicamente pela história e exame físico, resposta a anticolinesterásicos e imunossupressão. Os pacientes foram classificados segundo a classificação de Osserman modificada ${ }^{1}$. Classe I é definida por acometimento somente da musculatura extraocular. Classe IIA compreende os pacientes com acometimento discreto da musculatura sistêmica além do acometimento da musculatura extraocular. Na classe IIB há acometimento da musculatura bulbar e da musculatura sistêmica.. Classe III é caracterizada por miastenia generalizada grave e fulminante com acometimento bulbar. Na classe IV são incluídos pacientes que apresentam fraqueza muscular generalizada e bulbar em estágio avançado da doença.

Os pacientes foram vistos em consultório particular, no Serviço de Neurologia do Hospital das Clínicas da UFMG e no Serviço de Neurologia do Hospital Júlia Kubitscheck. As timectomias foram realizadas por via esternal.

Os resultados das timectomias foram categorizados somente em remissão e não remissão. Remissão foi definida como ausência de sintomas sem medicamentos. Não foi indicada timectomia em qualquer paciente com forma ocular pura. Os pacientes foram medicados com um regime variável de anticolinesterásicos, corticóides e imunossupressores, antes e após timectomia.

\section{RESULTADOS}

Os dados epidemiológicos e clínicos dos grupos com e sem remissão estão na Tabela 1.

Havia 7 homens e 45 mulheres, com idades de 15 a 47 anos, média de 27,0 anos, desvio padrão 7,8 . Cinco entre os 7 homens e 20 entre as 45 mulheres apresentaram remissão, com um indice total de $48 \%$ de remissões. O tempo de duração de doença foi de 1,8 e 4,3 anos nos grupos de remissão e nāo-remissāo, respectivamente. O tempo de seguimento foi de 5,5 anos em ambos os grupos. A remissão mais precoce ocorreu logo após a cirurgia em uma paciente e a mais tardia , também em uma paciente, 10 anos após . Não houve mortalidade cirúrgica; a única morte no grupo ocorreu 8 anos após a timectomia em consequência de infeç̧ão pulmonar.

Todas as remissões ocorreram em pacientes com menos de 4 anos de doença mas nem todos os pacientes com menos de 4 anos de doença entraram em remissão. No grupo que não apresentou remissão, 18 pacientes tinham menos de 4 e 9 mais de 4 anos de doença. Entre os 43 pacientes com menos de 4 anos de doença, 58\% entraram em remissão e $42 \%$ não entraram. Entre os 9 pacientes com mais de 4 anos de doença, nenhum entrou $\mathrm{cm}$ remissāo. Portanto, um tempo de doença de menos de 4 anos não garante uma remissão mas um tempo maior sugere fortemente a possibilidade de não-remissão. No grupo etário de menos de 20 anos de idade houve 6 pacientes com remissão e 5 sem remissão; no grupo etário de 21-30 anos, 14 tiveram remissão e 9 não tiveram; no grupo de 31-40 anos, ocorreram 3 remissões e 11 não-remissões e no grupo de 41-50 anos ocorreram 2 remissōes e 2 nāo-remissões. $O$ indice de remissāo cntre os pacientes com doença moderada foi de $68 \%$ e entre pacientes com forma grave foi de $38 \%$.

As remissões acumuladas foram 12 no fim do primeiro ano pós-operatório, 17 no fim do segundo ano, 20 ao fim do terceiro ano e 24 ao fim do quarto ano pós-operatório, uma remissão só tendo ocorrido 10 anos após a timcctomia, em uma paciente com o quadro clínico mais grave de todo o grupo. 
O estudo histológico dos timos pode ser obtido em 38 casos e é mostrado na Tabela 2. A alteração mais frequente foi hiperplasia linfóide, ocorrendo em $55 \%$ dos timos.

A prednisona foi usada por $44 \%$ dos pacientes que entraram em remissão e por $63 \%$ dos pacientes sem remissão. Duas pacientes usaram ciclofosfamida, uma no grupo de remissão.

\section{COMENTÁRIOS}

As alterações patológicas no timo de pacientes miastênicos foram observadas por Weigert

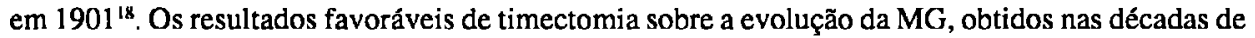
1940 e 1950 e o encontro de alterações no timo de pacientes operados, estabeleceram a relação entre o timo e a MG. Setenta por cento dos miastênicos apresentam alterações histológicas do timo, sendo a hiperplasia a mais comum ${ }^{4,12,14}$ enquanto timomas ocorrem entre 10 a $20 \%$ dos casos ${ }^{6.14,15.23}$. A ocorrência de MG após timectomia por timoma ${ }^{14}$ indica, porém, que o processo imunológico pode ser desencadeado em outros órgãos do sistema linfóide.

O índice de remissão entre os nossos pacientes de $48 \%$ é comparável aos índices relatados na literatura que variam de $8,3 \%$ a $54 \%^{3,13,16,18,19,20,22}$.

Tabela 1. Características dos pacientes timectomizados.

\begin{tabular}{|c|c|c|c|}
\hline & Remissão & Sem remissāo & Total \\
\hline Número & 25 & 27 & 52 \\
\hline \multicolumn{4}{|l|}{ Sexo } \\
\hline Masculino & 5 & 2 & 7 \\
\hline Feminino & 20 & 25 & 45 \\
\hline \multicolumn{4}{|c|}{ Idade em anos } \\
\hline$<20$ & 6 & 5 & 11 \\
\hline $21-30$ & 14 & 9 & 23 \\
\hline $31-40$ & 3 & 11 & 14 \\
\hline$>40$ & 2 & 2 & 4 \\
\hline
\end{tabular}

Tempo de doença

- Média

1,8 anos

4,3 anos

Menor

1 mês

4 meses

Maior

4 anos

19 anos

Gravidade da doença

Moderada(IIA)

Grave(IIB,III)

Tempo p/ remissāo

$\begin{array}{ll}\text { Média } & 2,3 \text { anos } \\ \text { Menor } & 0 \text { meses } \\ \text { Maior } & 10 \text { anos }\end{array}$

Tempo seguimento 
Tabela 2. Histologia do timo em miastênicos timectomizados.

\begin{tabular}{lrrr} 
& Remissão & Sem remissão & Total \\
\cline { 2 - 5 } Normal & 5 & 1 & 6 \\
Hiperplasia & 13 & 8 & 21 \\
Atrofia & 4 & 7 & 11 \\
Desconhecido & 2 & 10 & 12 \\
\hline
\end{tabular}

As remissões ocorreram apenas em pacientes com menos de quatro anos de doença. Entre os nove pacientes com mais de quatro anos de doença nenhum apresentou remissão após a timectomia.A influência do tempo de doença nos resultados de timectomia para tratamento de mistenia gravis já fora observada por Keynes (citado em Eaton e Clagett ${ }^{7}$ ) que relatou um tempo médio de doença de menos de cinco anos nos casos de melhora e de mais de cinco anos nos casos sem resposta. Todavia, Papatestas et al. ${ }^{19}$ encontraram nove pacientes com mais de cinco anos de doença entre 28 remissões. Buckberg et al. ${ }^{3}$ não identificaram remissão em qualquer paciente com mais de seis anos de doença. Por outro lado, Hatton et $\mathrm{al}^{9}$ não encontraram relaçăo entre melhora e tempo de doença.Durelli et al ${ }^{6}$ não observaram diferença de taxas de remissão em pacientes com menos ou mais de um ano de doença enquanto Genkins et al. ${ }^{8}$ observaram que os pacientes com menos de um ano de doença respondiam melhor à timectomia que os pacientes com mais de um ano. Olanow et al. ${ }^{15}$ obtiveram um indice de remissāo de $61 \%$ entre 47 pacientes timectomizados dos quais apenas dois tinham mais de quatro anos de doença. Nossos resultados reiteram a importância da timectomia precoce, devendo ela ser feita no máximo até quatro anos após o início da doença. Embora a reação autoimune da MG se origine no timo , quase certamente se generaliza para o sistema imunológico periférico nos estágios mais avançados da doença ${ }^{10}$. A ausência de remissão em nossos pacientes após mais de quatro anos de doença indica que após este tempo a generalização já ocorreu em todos. Todavia, o número de pacientes é pequeno para uma conclusão definitiva e a timectomia deve ser indicada nestes casos. A ausência de remissão em $42 \%$ dos pacientes com menos de quatro anos de doença indica que a generalização da resposta imunológica pode ocorrer antes de quatro anos.Não acreditamos que a ausência de remissão possa ser devida a tecido tímico não removido pela cirurgia pois todas as timectomias foram feitas por via transesternal, com ampla visualização das estruturas mediastinais.

O uso de imunossupressores não teve influência sobre a tendência para a remissão, tendo sido usado em somente $44 \%$ dos pacientes que entraram em remissão.

Devido aos progressos das técnicas e cuidados operatórios com consequente baixas morbidade e mortalidade, a timectomia tornou-se ao longo dos anos cada vez mais importante no tratamento da MG e este procedimento deve ser oferecido a todos miastênicos em condições cirúrgicas, a menos que eles tenham a forma ocular pura, sintomas mínimos ou sejam idosos e os nossos dados indicam que a cirurgia seja feita nos quatro primeiros anos de sintomas. Não indicamos timectomia para miastênicos sem timoma com mais de 50 anos porque o timo nos idosos não contém tecido tímico ou apresenta involução acentuada ${ }^{20}$. Todavia, vários autores ${ }^{27,15,23}$ não acham que idade seja contraindicação para timectomia. É possível que com o conhecimento cada vez maior da patogênese da MG se torne possível determinar no futuro quais os pacientes que poderão se beneficiar pela timectomia.

Agradecimento- Os nossos agradecimentos ao Dr. José Sílvio Rezende pela realização da maioria das timectomias. 


\section{REFERÊNCIAS}

1. Assis JL, Marchiori PE, Zambom AA, Scaff M. Timectomia em pacientes com mais de 50 anos de idade: considerações a propósito de 21 casos.Arq Neuropsiquiatr 1990, 48 (Supl):60.

2. Assis JL, Marchiori PE, Zambom AA, Scaff M. Thymectomy for myasthenia gravis: evaluation of results in 282 patients. Rev Hosp Clin Fac Med S.Paulo 1992,47:117-120.

3. Buckberg GD, Herrmann C, Dillon JB, Mulder DG. A further evaluation of thymectomy for myasthenia gravis. J Thorac Cardiov Surg 1967, 53: 401-411.

4. Drachman DB. Myasthenia gravis. N Engl J Med 1978, 298:136-142.

5. Drachman DB. Medical progress: myasthenia gravis. N Engl J Med 1994, 330:1797-1810.

6. Durelli L, Maggi G, Casadio C, Ferri R, Rendine S, Bergamini L. Actuarial analysis of the occurrence of remissions following thymectomy for myasthenia gravis in 400 patients. J Neurol Neurosurg Psychiatry 1991, 54:406-411.

7. Eaton LM, Clagett OT. Present status of thymectomy in treatment of myasthenia gravis. Am J Med 1955, 19:703-717.

8. Genkins G, Papatestas AE, Horowitz SH, Kornfeld P. Studies in myasthenia gravis: early thymectomy. Electrophysiologic and pathologic correlations. Am J Med 1975, 58:517-524.

9. Hatton PD, Diehl JT,Daly BDT, Rheinlander HF, Johnson H, Schrader JB, Bloom M, Cleveland RJ. Transternal radical thymectomy for myasthenia gravis: a 15-year review. Ann Thorac Surg 1989, 47:838-840.

10. Hohlfeld R. Disorders of neuromuscular transmission. Curr Opinion Neurol Neurosurg 1990, 3:684-688.

11. Kaminski HJ, Maas E, Spiegel $P$, Ruff RL. Why are eye muscles frequently involved in myasthenia gravis? Neurology 1990, 40: 1663-1669.

12. Kirchner T, Tzartos S, Hoppe F, Schalke B, Wekerle H, Muller-Hermelimk HK. Pathogenesis of myasthenia gravis. Am J Pathol 1988,130:268-280.

13. Mulder DG, Hermann C Jr, Heesey J, Edwards H. Thymectomy for myasthenia gravis. Am J Surg 1983, 146:61-65.

14. Namba T, Brunner NG, Grob D. Myasthenia gravis in patients with thymoma, with particular reference to onset after thymectomy. Medicine 1978, 57: 411-433.

15. Olanow CW, Wechsler AS, Roses AD. A prospective sudy of thymectomy and serum acetylcholine receptor antibodies in myasthenia gravis.Ann Surgery 1982, 196:113-121.

16. Oosterhuis HJGH. Longterm effects of treatment in 374 patients with myastenia gravis. Monogr Allergy 1988, 25:75-85.

17. Oosterhuis HJG. The natural course of myasthenia gravis: a long term follow up study. J Neurol Neurosurg Psychiatry 1989, 52:1121-1127.

18. Osserman KE. Myasthenia gravis. New York: Grune \&Straton,1958.

19. Papatestas AE, Alpert LI, Osserman KE, Osserman RS, Kark AE. Studies in myasthenia gravis: effects of thymectomy. Results on 185 patients with nonthymomatous myasthenia gravis, 1941-1969. Am J Med 1971, 50:465-474.

20. Perlo VP, Arnason B, Castleman B. The thymus gland in elderly patients with myasthenia gravis. Neurology 1975, 25:294-295.

21. Rowland LP. Controversies about the treatment of myasthenia gravis. J Neurol Neurosurg Psychiatry 1980 , 43:644-659.

22. Scadding GK, Harvard CWH, Lange MJ, Domb I. The long term experience of thymectomy for myasthenia gravis. J Neurol Neurosurg Psychiatry 1985, 48:401-406.

23. Slater G, Papatestas AE, Genkins G, Kornfeld P, Horowitz SH. Thymectomy in patients more than forty years of age with myasthenia gravis. Surg Gynecol Obstetr 1978, 146:54-56

24. Schumm F, Wietholter H, Fateh-Moghadam A, Dichgans $J$. Thymectomy in myasthenia gravis with pure ocular symptoms. J Neurol Neurosurg Psychiatry 1985, 48:332-337.

25. Sommier FE, Keiding N, Paulson OB. Epidemiology of myasthenia gravis in Denmark. Arch Neurol 1991, 48:738-739. 